\title{
History of the discovery of the stimulated Raman effect at the Hughes research laboratories
}

\author{
Gisela Eckhardt ${ }^{\mathrm{a}}$ \\ 20737 Cool Oak Way, Malibu, CA 90265, USA
}

\begin{abstract}
Received 3 May 2012 / Received in final form 25 July 2012
Published online 23 October 2012

(C) The Author(s) 2012. This article is published with open access at Springerlink.com
\end{abstract}

\begin{abstract}
In September 2011 an article appeared in The European Physical Journal H: Historical Perspectives on Contemporary Physics [Zinth 2011] with the title "The long journey to the laser and its rapid development after 1960". It gave a rather brief description of Stimulated Raman Scattering, the Raman Laser. I was one of the people involved in its discovery and I think it might be of interest to learn how this discovery was made.
\end{abstract}

In 2012 a half-century will have passed since the birth of the Raman laser. Its advent, about two years after the first demonstration of stimulated emission in ruby, opened up a much larger choice of wavelengths than had been available to experimenters before. In addition, the unique ability of the Raman laser to shift the wavelength of a high power laser to another wavelength more appropriate for a particular task, has led to its widespread use e.g. in such applications as making range finders eye safe for military personnel, submarine and optical fiber communication, remote analytical control of chemical processes in chemical plants, and many more.

In the spring of 1962 E.J. Woodbury and W.K. Ng of Hughes Aircraft Company in Culver City discovered that laser lines with longer wavelengths than the ruby laser line appeared in the output of their giant pulse ruby laser. They were not equipped, in their laboratory in Culver City, to do very extensive optical investigations. When, after several months, they could not find the cause for these new laser lines, Woodbury disclosed his discovery to George Smith, who was then associate director of the Hughes Research Laboratories (HRL) in Malibu. George Smith asked Fred J. McClung, Robert W. Hellwarth, and Daniel Weiner to investigate Woodbury's discovery. At some point, S.E. Schwarz joined the group as a summer student. But they did not find the source of the new laser lines either. Again several months later, I was consulted by McClung, who told me what had been found so far, and asked me to run an absorption spectrum of a laser ruby in the near infrared. I not only ran the spectrum but also went to the UCLA library and looked up the energy level diagrams of all the substances inside the laser cavity: ruby, quartz, and nitrobenzene. When I compared these diagrams with the wave numbers of the new laser lines, I realized that

a e-mail: egisela1@gmail.com 
of all the levels, only one provided an explanation: nitrobenzene had a Raman-active level whose value (or its multiples) corresponded to the wave number shifts between the ruby laser line and the new ones. I told McClung what I had found. I did not hear from him again until about four weeks later, when he left a note on my desk that he was looking for me. When I contacted him, he told me that he had not been able to find the energy level diagram of ruby that I had given to him, but had located this information elsewhere in the meantime. I reiterated that I felt the ruby had nothing to do with the new effect, and I realized only then, after a brief conversation, that McClung continued to believe that the unexplained lines were due to the ruby. During that summer Professor Morrel H. Cohen of the University of Chicago was at HRL as a consultant. I talked to him about my interpretation of the lines, that they appeared to be produced by a Raman active energy level of $\mathrm{NO}_{2}$ from the nitrobenzene of the Kerr cell that played the role of high-speed shutter in the cavity of the Q-switched ruby laser. I also suggested a relatively straightforward experiment that would prove or disprove my claim. Specifically, I pointed out that taking the Kerr cell out of the laser cavity and replacing it with another shutter would result in the disappearance of the lines if they were Raman emissions from the nitrobenzene in the cell. Cohen asked me to go with him to John Richardson, who was then Hellwarth's department head. In my presence, Cohen repeated to Richardson what I had told him. Richardson immediately called Hellwarth and McClung and the story was told a third time. At first McClung insisted that he would only do the Kerr-cell removal experiment I had suggested after a series of other experiments he had on his to-do list, and which he considered to be much more important. Finally, the others present were able to persuade him to prepare "my" experiment right away. He replaced the Kerr cell with a Pockels cell, and indeed the new laser lines disappeared.

In order to prove that the $\mathrm{NO}_{2}$ vibration of nitrobenzene, which produced the new laser lines, indeed had the largest Raman scattering cross section of all nitrobenzene vibrations, I suggested setting up a normal Raman scattering experiment, using the giant pulse ruby laser as light source, and looking for the most intense Raman shifted line at right angles to the exciting laser beam. However, after the successful experiment with the Pockels cell, McClung had left to go to the WESCON Convention in Los Angeles and then on vacation for a week.

Since McClung had left, George Smith came to me and asked me to set up the Raman scattering experiment. However, Weiner refused to touch the giant pulse laser without McClung's permission and pointed out that McClung had a key which was needed to operate their spectrometer for the visible range. I therefore drove to the WESCON, tracked down McClung, got instructions from him on how to use the equipment, and obtained the key. I set up the experiment with the aid of Schwarz and then had to leave to go to an APS meeting in Seattle (August 27 to 29, 1962.) When I returned, McClung was still on vacation but the experiment had been done by Schwarz and Weiner. It showed that the $1345 \mathrm{~cm}^{-1}$ level of nitrobenzene produced the strongest Raman line, just as I had expected. On the day of my return (August 30), Smith asked Hellwarth, in my presence, who had first suggested that the new laser lines came from the nitrobenzene. Hellwarth answered: "Gisela Eckhardt said that."

The same day, our HRL patent attorney came to me, said he had been asked by George Smith to see me, and that I should write a patent disclosure jointly with E.J. Woodbury. The patent application was made on October 4, 1962 in both our names and U.S. Patent No. 3, 371, 265 was granted on February 27, 1968. A partial facsimile of this patent is shown in Figure 1.

It took six years to receive this patent, because it was rejected by the patent examiner three times, claiming that the Raman laser was an obvious idea after a paper was published where a laser was used as a light source for Raman spectroscopy [Porto 1962], and that it was only another parametric amplifier and that 


\section{United States Patent Office}

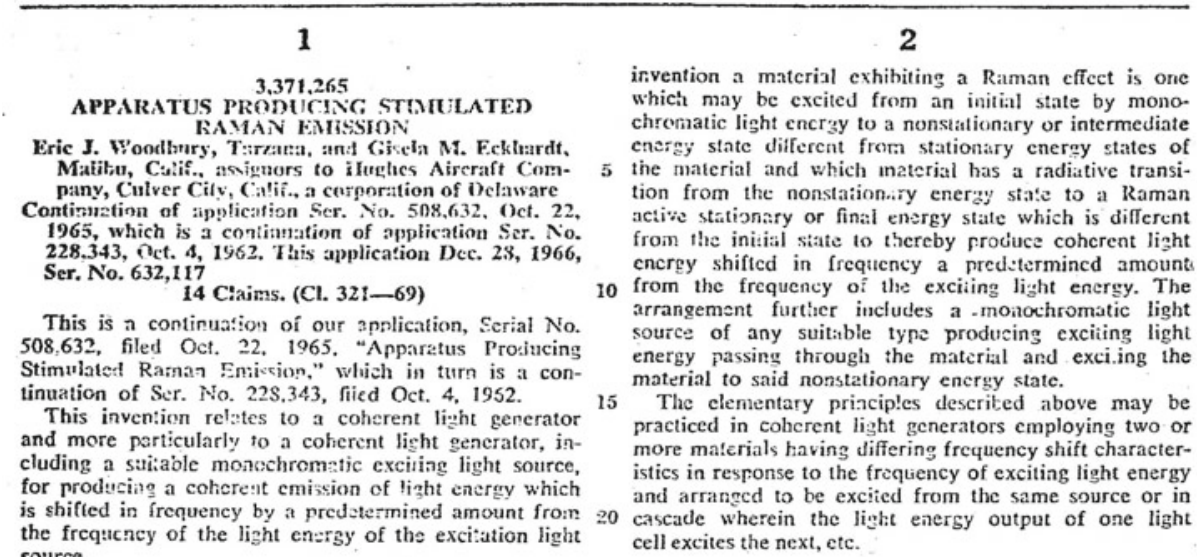
source.

Prior art ccherent light scurces each generally comprise a laser cell of fluorescent material which is disposed in an ontical resonator and excitcd by pempring 25 means, generally a broadband linht scurce, to a stationary. eneray state. This may be explaircd by iadicating that the atoms, or ions as the casa may be. of the laser cell material are excited or pumped frem what may be called a ground erierzy level or state to a stationary clectronic so energy level or state by means of an optical pemping source having the energy correcponding to the difference between the energy represented by the ground energy state and the enerpy in the rezion of the aforementioned stationary electronic cnergy state. The atoms thus excited 5 then decay from the stationary electronic energy state to a lower energy state, or in other cases to the orourd energy state, depending on the type of fuorescent matcrial used. In cach of the above cases, the atoms decaying from a stationary or metastable electronic enerzy state 4 to the greund or lower energy state will pioduce stimulated emission. Thas the prior art nroviles a mechanism for funneling energy from a broacband incoherent light source into a morochrematic coherent radiation havins a discrele frequency. The frectitency of the stimulated emission is in every way dependent upon the material comprising the laser ce!l an 1 , if the cell is made to radiate energy at all, it will always radiate this energy at a frequency characteristic of the material and at no other.

The tcachings of the prior art are extended according to the present invention in the utilization of a monochromatic licht sonrce to preduce coherent linht at frequencies shifted a predetermined amount frem the frequency of the light encray produced by the exciting light 55 source.

One object of the present invention is to provide an improved co!tercent light generator.

Another chiect of the prescat invention is to provide a coherent light ecnerator capable of radiating coherent 60 light at a frecuency shifted a predetermined amount from the frequency of the light energy of an excitation light source.

Siill ancther object of the present invention is to provide a coherent liwht seneristor producing one or 65 more frequenzics shifted different amounts from the frequency of the excitation lieht soaree.

These and o:her obiecives are xhi:ved in a coherent light generator according to one enthodim:nt of this invention cemrixing ; material which is sub-tantially trans. io parent to the frequency of the exciting litht encray and which exhibits a Raman effect. According to this

Fig. 1. Partial facsimile of U.S. Patent 3, 371, 265. This part describes the prior art of coherent light sources and the advancement achieved in this field with the present invention. 
there was nothing patentable about it. All my explanations did not convince the patent examiner. Finally I called three prominent scientists in the laser field who I knew and asked them for affidavits: C.H. Townes, who had gotten the Nobel prize for the maser/laser principle, B.A. Lengyel, who wrote the first book on lasers, and S.P.S. Porto, the co-author of the paper "Ruby optical maser as a Raman source". The patent was granted shortly after the patent office received the three affidavits.

Subsequently, after McClung's return, a number of other organic substances were put inside the laser cavity, and many were found to produce new laser lines as well.

For a while, another explanation for the appearance of the laser lines had to be considered. Hellwarth had pointed out that the absorption spectra of all of the substances which produced the new effect show a small absorption due to the 5 th harmonic of a $\mathrm{C}-\mathrm{H}$ vibration in the vicinity of the ruby laser line, and induced fluorescence would therefore be possible. For the crucial experiment to distinguish between stimulated fluorescence and stimulated Raman scattering, I suggested the use of deuterated benzene, $\mathrm{C}_{6} \mathrm{D}_{6}$, to remove the 5 th harmonic absorption from the vicinity of the ruby line. The experiment was performed and its outcome favored stimulated Raman scattering as the correct explanation of the new effect. The joint effort and its results are described in [Eckhardt 1962]. This paper, received by the editor Oct. 1, 1962, was the first to explain this new effect. The task of actually writing the paper was undertaken by Hellwarth.

In summary, the sequence of events was as follows: the new laser lines were discovered accidentally by Woodbury and $\mathrm{Ng}$, who were unable to explain their origin over a period of several months. On learning of their discovery, I suggested the correct explanation for the new laser lines. In the light of the mechanism I suggested, I proposed three crucial experiments to prove its correctness. Two of these experiments were conducted by McClung and his group and one was set up by me with the help of Schwarz, and actually performed by Schwarz and Weiner. The giant-pulse laser and the spectrometer for the visible range belonged to McClung. I ran the absorption spectra of the substances involved, while all experiments involving the giant-pulse laser were done by McClung and his coworkers. The manuscript was written by Hellwarth. The basic patent for the Raman laser was awarded to Woodbury and me as the sole inventors.

\section{References}

Eckhardt, G., R.W. Hellwarth, F.J. McClung, S.E. Schwarz, D. Weiner, and E.J. Woodbury. 1962. Stimulated Raman scattering from organic liquids. Phys. Rev. Lett. 9: 455-457

Porto, S.P.S. and D.L. Wood. 1962. Ruby optical maser as a Raman source. J. Opt. Soc. Am. 52: 251-252

Zinth, W., A. Laubereau and W. Kaiser. 2011. The long journey to the laser and its rapid development after 1960. Eur. Phys. J. H 36: 153-181

Open Access This is an open access article distributed under the terms of the Creative Commons Attribution License (http://creativecommons.org/licenses/by/3.0), which permits unrestricted use, distribution, and reproduction in any medium, provided the original work is properly cited. 